\title{
UV-protection of wood surfaces by controlled morphology fine-tuning of $\mathrm{ZnO}$ nanostructures
}

\section{Journal Article}

Author(s):

Guo, Huizhang; Fuchs, Peter; Cabane, Etienne; Michen, Benjamin; Hagendorfer, Harald; Romanyuk, Yaroslav E.; Burgert, Ingo

Publication date:

2016-08

Permanent link:

https://doi.org/10.3929/ethz-b-000259380

Rights / license:

In Copyright - Non-Commercial Use Permitted

Originally published in:

Holzforschung 70(8), https://doi.org/10.1515/hf-2015-0185 
Huizhang Guo*, Peter Fuchs, Etienne Cabane, Benjamin Michen, Harald Hagendorfer, Yaroslav E. Romanyuk and Ingo Burgert*

\section{UV-protection of wood surfaces by controlled morphology fine-tuning of $\mathrm{ZnO}$ nanostructures}

DOI 10.1515/hf-2015-0185

Received August 25, 2015; accepted November 24, 2015; previously published online January 7, 2016

Abstract: One of the most significant limitations for a wider utilisation of the renewable and $\mathrm{CO}_{2}$-storing resource wood is its low ultraviolet (UV) light stability. The protection of the wood surface without altering its aesthetic appeal requires an optically transparent but UV protective coating which should be strongly attached to the rough and inhomogeneous substrate. For this purpose, $\mathrm{ZnO}$ nanostructures were deposited onto the wood surface via a chemical bath deposition process. The morphology of crystalline $\mathrm{ZnO}$ was controlled by aluminium nitrate or ammonium citrate in the growth step resulting in nanorod arrays or platelet structures, respectively. Detailed structural, chemical and mechanical characterisations as well as accelerated weathering exposure revealed the effective performance of the platelet structure, which formed a dense and thin $\mathrm{ZnO}$ coating on spruce. The total colour change ( $\Delta E$ in the CIE system) was calculated to be 20.5 for unmodified wood, while it was about three for the modified samples after 4 weeks accelerated weathering test. Moreover, the ZnO coating also suppressed crack initiation and propagation indicating a substantial increase in durability.

\footnotetext{
*Corresponding authors: Huizhang Guo and Ingo Burgert, Wood Materials Science, Institute for Building Materials, ETH Zürich, Stefano-Franscini-Platz 3, 8093 Zürich (Switzerland); and Applied Wood Materials, Empa-Swiss Federal Laboratories for Materials Science and Technology, Überlandstrasse 129, 8600 Dübendorf (Switzerland), e-mail: huguo@ethz.ch (H. Guo), iburgert@ethz.ch (l. Burgert)

Peter Fuchs, Harald Hagendorfer and Yaroslav E. Romanyuk: Laboratory for Thin Films and Photovoltaics, Empa-Swiss Federal Laboratories for Materials Science and Technology, Überlandstrasse 129, 8600 Dübendorf (Switzerland)

Etienne Cabane and Benjamin Michen: Wood Materials Science, Institute for Building Materials, ETH Zürich, Stefano-Franscini-Platz 3, 8093 Zürich (Switzerland); and Applied Wood Materials, EmpaSwiss Federal Laboratories for Materials Science and Technology, Überlandstrasse 129, 8600 Dübendorf (Switzerland)
}

Keywords: chemical bath deposition, CIE $L^{*} a^{*} b^{*}$ system, colour change upon UV irradiation, surface coating by dense $\mathrm{ZnO}$ layer, UV protection of wood, weathering of wood, wood surface, zinc oxide ( $\mathrm{ZnO}), \mathrm{ZnO}$ nanorods, $\mathrm{ZnO}$ platelets

\section{Introduction}

Wood is an excellent and widely used sustainable material for construction and furniture, but it is prone to degradation under UV exposure. The UV-induced degradation leads to colour change and surface alteration, and even to surface destruction in presence of water, which strongly affects the reliability of wood in various applications. Among the three main wood constituents (cellulose, hemicelluloses and lignin), the aromatic polymer lignin is the best UV absorber (Deka et al. 2008). As an example, the absorption spectrum of lignin from Norway spruce (Picea abies (L.) Karst.) displays a maximum absorption at $280 \mathrm{~nm}$ with a tail extending to $\sim 350 \mathrm{~nm}$ (Sander and Koch 2001). As a result, in the case of unprotected wood surfaces, UV light from the solar spectrum induces lignin degradation via photo-oxidation. The natural polymers undergo bond cleavage and hydrogen abstraction resulting in the formation of radicals or peroxides which finally decompose and generate the coloured and hydrophilic by-products (chromophores) (Müller et al. 2003). Lignin is fragmented into low molecular weight species (such as water soluble polyphenols), which can be washed away by rain in outdoor applications. This exposes the underlying cell wall structure and leads to further degradation of the surface, which is then more prone to fungal attack (Hernandez and Evans 2015). Hence, the photochemical reactions result in a significant surface alteration of wood, with a loss of gloss and surface roughening (George et al. 2005; Zahri et al. 2007; Liu et al. 2015).

To address this challenge and reduce the photo-degradation of wood, different techniques to protect wood surfaces have been developed, including chemical modification of the wood polymers, surface treatments with 
additives (organic and inorganic UV absorbers, radical scavengers), and finishing (varnishes and opaque coatings). Chemical modification of wood such as acetylation and silylation (Plackett et al. 1992) bind chemicals to the cell wall polymers which can stabilise the wood colour (Rowell 2006; Baur and Easteal 2013; Lahtela and Kärki 2014). For example, Baur and Easteal (2013) used $\alpha$ - or $\gamma$ methacryloxysilanes and $\gamma$-epoxysilane to suppress free radical generation under UV exposure. Sander and Koch (2001) applied acetic anhydride and a 2-step hydrothermal treatment to modify Norway spruce samples, which retarded the UV-degradation of lignin. In another study, acetylated wood exhibited enhanced colour stabilisation when compared to their non-acetylated counterpart for the first 28 days in the UV chamber, but thereafter, the stabilisation could not be retained and discolouration began (Hon 1995). Surface modifications by silylation, thermal and copper ethanolamine treatment altered the colour of the wood specimens (Deka et al. 2008; Srinivas and Pandey 2012).

Nowadays, there is an increasing attention dedicated to wood modification with inorganic components (Sun et al. 2010; Mahr et al. 2013; Lu et al. 2014). For example, $\mathrm{SiO}_{2}$ nanoparticles with hydrolyzed hexadecyltrimethoxysilane or $\mathrm{Al}(\mathrm{OH})_{3}$ micro/nanospheres were applied to make wood surface hydrophobic (Wang et al. 2013) or fire resistance (Wang et al. 2014). Coating wood with metallic Ag nanoparticles and fluoroalkyl silane resulted in conductive and hydrophobic wood surfaces (Gao et al. 2016). A few studies report wood surface coatings based on inorganic nanoparticles acting as UV absorbers (Rao et al. 2016). Generally, these nanoparticles are semiconductor materials which absorb UV light via electron transition between conduction band and valence band but are transparent to visible light (Aloui et al. 2007; Auclair et al. 2011; Fu et al. 2015). For instance, southern pine specimens were vacuum impregnated by nano-ZnO dispersions for UV protection (Clausen et al. 2010). $\mathrm{TiO}_{2}$ nanoparticles achieved by a sol-gel process were deposited onto wood surfaces via dip-coating and subsequent annealing to block UV irradiation (Rassam et al. 2012). The main drawback of such treatments is the leaching of added particles over time, lowering the protection efficiency, and necessitating regular application of new layers. Facing this challenge, a mixture of inorganic UV absorbers in a transparent organic coating to obtain highly durable and efficient UV protection coatings was reported recently (Auclair et al. 2011). ZnO-based acrylate coatings were applied to impregnate wood to reduce yellowing under UV exposure (Weichelt et al. 2010). Salla et al. (2012) dispersed ZnO nanoparticles in maleic anhydride modified polypropylene or polyurethane to prepare UV barrier coatings. The prospective use of nanofibrillated cellulose as carrier of UV absorbers for wood coating was described by Grüneberger et al. (2014a,b). Following a similar approach, $\mathrm{TiO}_{2}$ nanoparticles incorporated into water-based acrylic systems, and $\mathrm{CeO}_{2}$ based nano-composite (Veronovski et al. 2013; Auffan et al. 2014) were applied onto wood surfaces for a long-term resistance against weathering. However, the self-degradation of the applied polymers caused by sunlight exposure limits their long-term performance in photo-stabilizing wood.

In-situ coating of the substrate with a $\mathrm{ZnO}$ layer via a liquid phase route, which has been originally developed for solar cells or transparent conductive electrodes (Law et al. 2005; Greene et al. 2006; Hoang et al. 2013; Hagendorfer et al. 2014) would be a facile and promising method for wood UV protection. Yu et al. (2010) grew nanorods on wood surface via a two-step process, consisting of the generation of a seed layer on the wood surface followed by further particle growth. Sun et al. (2012) developed a one-pot hydrothermal method to grow highly ordered $\mathrm{ZnO}$ nanorod arrays onto the wood surface, which improved UV resistance. Aligned $\mathrm{ZnO}$ nanorods were fabricated on wood surfaces via a similar process by Liu et al. (2013). However, the morphology and the crystallinity of $\mathrm{ZnO}$ nanostructures on the wood surface is difficult to control, and the interaction between the inorganic coating and wood surface might not be sufficiently tight with regard to weathering stability. Further, $\mathrm{ZnO}$ nanorod arrays can show a strong scattering of visible light (Law et al. 2005, 2006), which diminishes the aesthetic appearance of the wood surfaces.

In this article, we report on increasing the UV-stability of wood by a coating that almost retains the natural aesthetic appearance, through the growth of an inorganic $\mathrm{ZnO}$ layer onto the rough and inhomogeneous wood surface. The surface of Norway spruce was coated by a conformal $\mathrm{ZnO}$ layer via chemical bath deposition (CBD), with $\mathrm{ZnO}$ powder and ammonium hydroxide as precursors in aqueous solution. CBD is a known soft chemical method, which is promising for the preparation of metal oxide nanomaterials with controllable morphologies and sizes, as well as allows for rather low temperature and ambient reaction condition (Niederberger et al. 2004; Hoang et al. 2013). It was demonstrated that the c-axis growth of $\mathrm{ZnO}$ crystal can be suppressed by a structure directing agent (Tian et al. 2003) to achieve platelet structures that result in a dense and highly crystalline $\mathrm{ZnO}$ film on the wood surface. The performance of the material will be tested by surface analysis and weathering. The interface between 
wood and $\mathrm{ZnO}$ should also be carefully studied by means of electron microscopy.

\section{Materials and methods}

Wood specimen preparation: Spruce wood ( $P$. abies) slices [radial $(\mathrm{R}) \times$ tangential $(\mathrm{T}) \times$ longitudinal $(\mathrm{L})$ dimensions: $5 \times 25 \times$ $40 \mathrm{~mm}^{3}$ ] were firstly ultrasonically cleaned in a mixed solution of ethanol and acetone (with a volume ratio of 15:1) for $15 \mathrm{~min}$. After drying at $65^{\circ} \mathrm{C}$ for $12 \mathrm{~h}$, they were stored in the artificial climate room with a temperature of $20^{\circ} \mathrm{C}$ and a relative humidity of $65 \%$.

Surface seeding: The seed layer was prepared by dipping the wood slices into an aqueous solution containing $5 \mathrm{M} \mathrm{NH}_{3}(28 \%$ in water, Alfa Aesar, Karlsruhe, Germany) and $50 \mathrm{mM} \mathrm{ZnO}$ (p.a. grade, Sigma-Aldrich, the Netherlands) at room temperature (r.t.) for $3 \mathrm{~min}$ before transferring into the oven at $110^{\circ} \mathrm{C}$ for $2 \mathrm{~min}$. In order to obtain a dense and continuous $\mathrm{ZnO}$ coating, this procedure was repeated three times to ensure that the wood surface was completely seeded.

Chemical bath deposition (CBD): In a typical procedure, the precursor solution was prepared as follows: $\mathrm{NH}_{4} \mathrm{NO}_{3}$ (8.004 g, p.a. grade, Sigma-Aldrich, Belgium), ZnO powder (8.139 g, p.a. grade, Sigma Aldrich, the Netherlands) and $132 \mathrm{ml}$ of $\mathrm{NH}_{4} \mathrm{OH}$ (28\% in water, Alfa Aesar, Karlsruhe, Germany) were loaded into a plastic bottle before pouring deionized water until the total volume reached 21 . The precursor solution was stirred for $12 \mathrm{~h}$ and stored at r.t. until usage. For the formation of dense $\mathrm{ZnO}$ coating, $200 \mathrm{ml}$ of precursor solution was filtered ( $1 \mu \mathrm{m}$ glass fibre filters) into a glass flask followed by adding $0.170 \mathrm{~g}$ of ammonium citrate (p.a. grade, Alfa Aesar, Karlsruhe, Germany). The $\mathrm{pH}$ value of the precursor solution was about 11.4. After pre-heating at $90^{\circ} \mathrm{C}$ for $15 \mathrm{~min}$, the seeded spruce slices were immersed into the growth solution. Chemical bath deposition was carried out at $90^{\circ} \mathrm{C}$ for $150 \mathrm{~min}$. After the chemical bath deposition, the wood samples were removed from the solution, washed with water, and dried in an oven at a temperature of $65^{\circ} \mathrm{C}$ for $12 \mathrm{~h}$. For the formation of $\mathrm{ZnO}$ nanorod coating, $200 \mathrm{ml}$ precursor solution was filtered into a glass flask followed by adding aluminium nitrate nonahydrate ( $0.008 \mathrm{~g}$, Sigma Aldrich, Germany) to form a precursor solution with an aluminium ions concentration of $0.1 \mathrm{mM}$. Then, the seeded spruce slice was immersed into the growth solution. Deposition was carried out at $90^{\circ} \mathrm{C}$ for $30 \mathrm{~min}$. After the chemical deposition, the wood samples were washed with water and dried in an oven at a temperature of $65^{\circ} \mathrm{C}$ for $1 \mathrm{~h}$.

UV irradiation: UV protection efficiency of $\mathrm{ZnO}$ coating was assessed in a UV curing chamber (UVACUBE 400, Honle Goup, Gräfelfing, Germany) by short-time irradiation. The lamp generates sunlight simulation spectrum with an electrical input of $400 \mathrm{~W}$. One hundred and two hours of UV exposure was carried out with interruptions for colour measurements.

Accelerated weathering test: Coated and unmodified wood samples were exposed to an artificial weathering test in the QUV Accelerated Weathering Tester (Q-LAB, Miami, USA), which is equipped with UVA-340 lamps, water spraying devices, and a heating unit. An exposure cycle of 1 week consists of a condensation period followed by a sub-cycle of water spraying and UV-A 340 irradiation according to the European standard EN 927-6:2006 (E).

Colour measurement: Colour evaluation of the wood samples before and after UV exposure and water spraying were determined in the CIE $L^{*} a^{*} b^{*}$ system with the Chroma Meter CR-200 (Minolta, Miami, Japan). $L^{*}$ represents the lightness from black (0) to white (100), while $a^{*}$ and $b^{*}$ are the chromaticity indices, where $+a^{*}$ is the red, $-a^{*}$ is the green, $+b^{*}$ is the yellow, $-b^{*}$ is the blue direction. The total colour change is defined as $\Delta E=\sqrt{\Delta L^{2}+\Delta a^{2}+\Delta b^{2}}$.

FT-IR instrument: Bruker Tensor 27 (Bruker, Ettlingen, Germany) equipped with an ATR module. The $\mathrm{ZnO}$ coated wood surface was ultrasonically treated in a $2 \% \mathrm{HCl}$ solution for $1 \mathrm{~min}$ to remove the coating. Then, it was washed with water and dried in the oven at $65^{\circ} \mathrm{C}$ for $3 \mathrm{~h}$ before FT-IR measurement. Cross sections of the samples were smoothed by a rotary microtome (Leica Ultracut, Wetzlar, Germany). Depth profiles were acquired by means of a TENSOR II FT-IR Spectrometer equipped with HYPERION 3000 FT-IR Microscope (Bruker, Ettlingen, Germany). The spectra were normalised to the maximum band at around $1060 \mathrm{~cm}^{-1}$. To study the binding of zinc ammonia complexes, a treatment was carried out by dipping the wood slice into the typical seeding solution for $5 \mathrm{~min}$ before getting out and drying in the open air for $3 \mathrm{~h}$. Then, FT-IR spectra were acquired.

Nano- and microstructural characterisations: Surface topographies were analysed by a scanning electron microscope (SEM, FEI Quanta 200F, Hillsboro, USA). Broad ion beam (BIB) cross sectioning was applied for preparing accurate cross section surfaces in ion milling systems (Hitachi BIB 4000, Tokyo, Japan). The powder $\mathrm{X}$-ray diffraction (XRD) patterns of the coating on wood surface were acquired in Bragg-Brentano mode and in $\theta-2 \theta$ geometry with $\mathrm{Cu}-\mathrm{K} \alpha$ radiation on a PANalytical Empyrean diffractometer, Almelo, the Netherlands. Transmission electron microscopy (TEM) sections were prepared by focused ion beam scanning electron microscopy (FIB-SEM, Zeiss NVision 40, Cambridge, UK) and mounted onto copper holder without any support. High angle annular dark field scanning transmission electron microscopy (HAADF-STEM) analysis was performed on a FEI Talos ${ }^{\mathrm{TM}}$ (Hillsboro, USA) with energy dispersive spectroscopy (EDS; $200 \mathrm{kV})$.

\section{Results and discussion}

Figure 1 illustrates the formation of $\mathrm{ZnO}$ nanorod arrays and platelets on the wood surface with either aluminium nitrate or ammonium citrate in the growth process. In the first step of the modification, the seeding of the wood surface with $\mathrm{Zn}\left[(\mathrm{OH})_{\mathrm{x}}\left(\mathrm{NH}_{3}\right)_{\mathrm{y}}\right]^{2 \cdot \mathrm{x}}$ complexes takes place. These complexes are formed by dissolving $\mathrm{ZnO}$ powder into ammonium solution (Danilov et al. 1976) and may bind to wood via coordination effects with functional groups (Figure 1a), such as hydroxyl (Katepetch et al. 


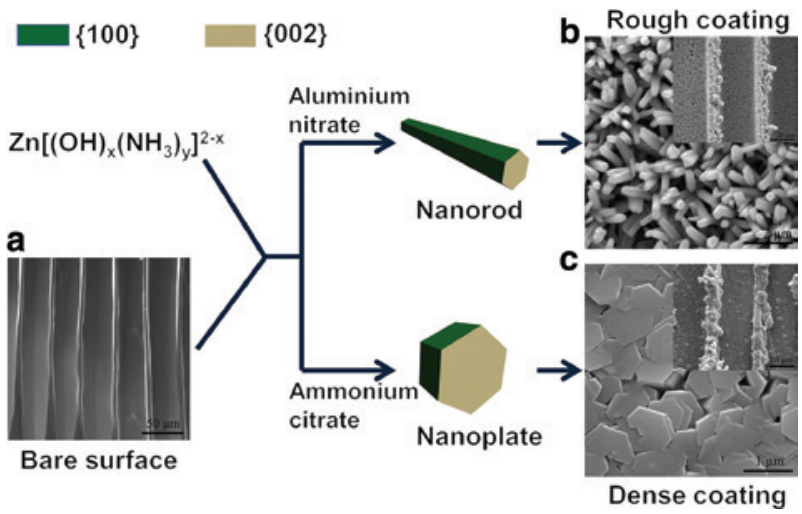

Figure 1: Schematic illustration of the shape selective deposition of $\mathrm{ZnO}$ nanostructures on the wood surface. SEM image of an unmodified Norway spruce surface (a), ZnO nanorod array coating formed in the presence of aluminium nitrate (b) and the dense $\mathrm{ZnO}$ coating with platelet like structure (c). The insets in (b) and (c) are the corresponding low magnification SEM images.

2013) and carbonyl groups (Avirah et al. 2008). After heat treatment, a thin $\mathrm{ZnO}$ layer is formed, which acts as a seed layer and enables the growth of the $\mathrm{ZnO}$ nanostrucutres on the wood surface in the second step. The presence of $\mathrm{Al}^{3+}$ doping ions in the solution suppresses the growth of $\{100\}$ planes of $\mathrm{ZnO}$ nanocrystals, leading to the formation of nanorods (Joo et al. 2011) as illustrated in Figure 1b. The morphology of $\mathrm{ZnO}$ nanostructures can be adjusted during the growth process in presence of ammonium citrate forming a continuous film of $\mathrm{ZnO}$ platelets as depicted in Figure 1c. Here, the c-axis oriented growth is suppressed because citrate preferentially binds to the polar $\{002\}$ faces of hexagonal $\mathrm{ZnO}$ (Cho et al. 2009).

The two nanostructured coatings were further investigated by SEM (Figure 2). The images illustrate that the wood surface, i.e. the outer cell layer, is covered with a conformal $\mathrm{ZnO}$ film which also covers the lumen surface of the tracheids (Figure 2a and b). A similar result can be observed from the SEM images acquired on the transverse plane, which indicates that the $\mathrm{ZnO}$ coating follows the topography of the rough wood surface (Figure $2 \mathrm{c}$ and e). The higher magnification SEMimage (Figure 2d) of a spruce surface modified with $\mathrm{ZnO}$ platelets, shows a dense and continuous $\mathrm{ZnO}$ layer with an average thickness of about $3.5 \mu \mathrm{m}$ on the outer surface, while the surface of the inner, intact lumen is also covered by a $\mathrm{ZnO}$ film with a thickness of about $600 \mathrm{~nm}$. The latter indicates that the precursor solution penetrated through the outermost wood cell wall during the CBD process. A conformal layer with discrete nanorod structure is obtained for samples prepared in the presence of $\mathrm{Al}^{3+}$ ions (Figure 2e and $\mathrm{f}$ ).
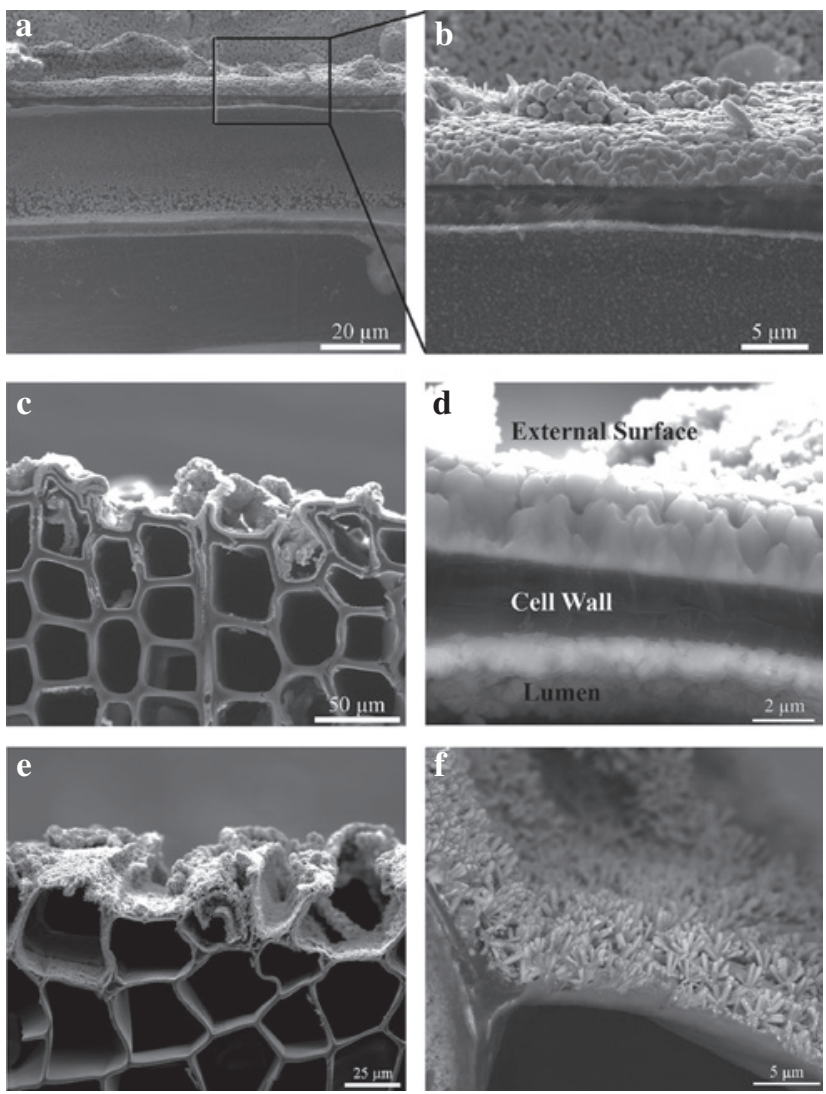

Figure 2: SEM images of the different $\mathrm{ZnO}$ nanostructers on wood. Wood cell structure with $\mathrm{ZnO}$ platelet coating (a); zoom in the squared region (b); the transverse plane of Norway spruce with dense $\mathrm{ZnO}$ coating (c); the most top cell wall with dense $\mathrm{ZnO}$ coating (d); transverse plane of Norway spruce with $\mathrm{ZnO}$ nanorod coating on the tangential plane (e); the most top cell wall with $\mathrm{ZnO}$ nanorod coating (f).

For in-depth analysis, the crystalline structure of the $\mathrm{ZnO}$ coatings on the wood surface was investigated by XRD. Spruce wood exhibits a couple of strong diffraction peaks at $16.4^{\circ}$ and $22.4^{\circ}$, which can be attributed to the crystalline region of cellulose (Figure 3, curve d). The XRD pattern of the seeded wood sample (curve c) shows no diffraction peak belonging to $\mathrm{ZnO}$. However, the intensity of the diffraction peaks of cellulose crystals becomes weak compared to bare spruce (curve d). This reveals that the wood surface was well covered with the $\mathrm{ZnO}$ seed layer after dipping into the zinc ammine solution and heat treatment, because the $\mathrm{ZnO}$ seed layer partly absorbs or blocks the incident X-ray. After the chemical bath deposition process, a series of diffraction peaks assigned to hexagonal ZnO (JCPDS 36-1451) were observed for both, microplatelets and nanorods (curve a and b). The diffraction peaks of cellulose crystals almost disappeared when the wood surface was covered by a continuous, 


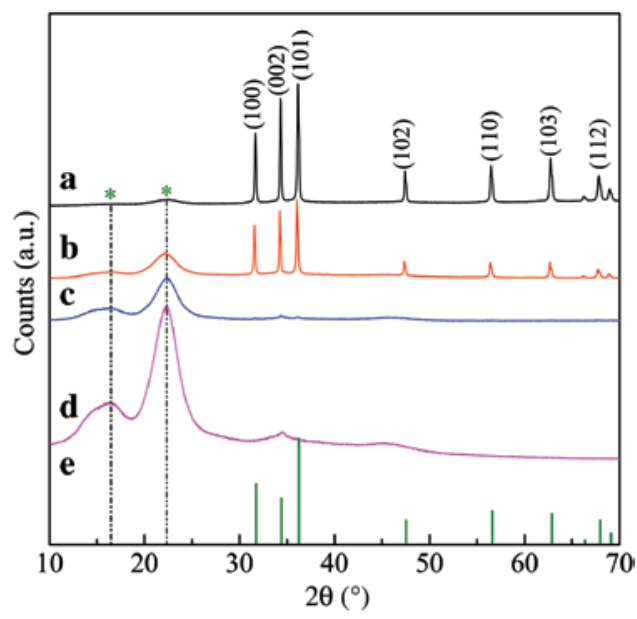

Figure 3: X-ray diffraction pattern of Norway spruce with a dense $\mathrm{ZnO}$ coating (a), with a $\mathrm{ZnO}$ nanorod coating (b), with a seed layer (c), and bare Norway spruce (d). The reference powder diffraction pattern of ZnO (JCPDS 36-1451) (e).

dense, and highly crystalline $\mathrm{ZnO}$ film (curve a). The XRD pattern of spruce wood with $\mathrm{ZnO}$ nanorod coating also exhibits the characteristic diffraction peaks of hexagonal $\mathrm{ZnO}$. However, the signal of crystalline cellulose is still apparent (curve b), which indicates that this surface coating is less dense and allows for the transmission of $\mathrm{X}$-rays. This is important because the highly crystalline and dense $\mathrm{ZnO}$ coating is of crucial relevance for transparency (Hagendorfer et al. 2014).

The dense and continuous $\mathrm{ZnO}$ coating (as visible in Figure 1c and Figure 2a) proved to be beneficial for the weathering resistance of the wood surface, which is discussed below. The coating obtained by $\mathrm{ZnO}$ platelets was characterised in more detail by TEM presented in Figure 4. A lamina for S/TEM analysis was cut by FIB to avoid mechanical artifacts. Low magnification TEM imaging demonstrates that the $\mathrm{ZnO}$ coating is tightly covering the cell wall surface without any crevices (Figure 4a). The selective area electronic diffraction pattern (SAED) confirms that the dense $\mathrm{ZnO}$ film grows along the [001] direction (Figure 4b). Because in the presence of ammonium citrate the growth of $\mathrm{ZnO}$ along the [001] direction is suppressed (Tian et al. 2003; Cho et al. 2009), the ZnO crystals on wood surface have the tendency to grow along the [100] direction, i.e. parallel to wood surface. This controlled crystal growth leads to the formation of a dense film by adjoining single crystals with a twinned boundary. The HRTEM
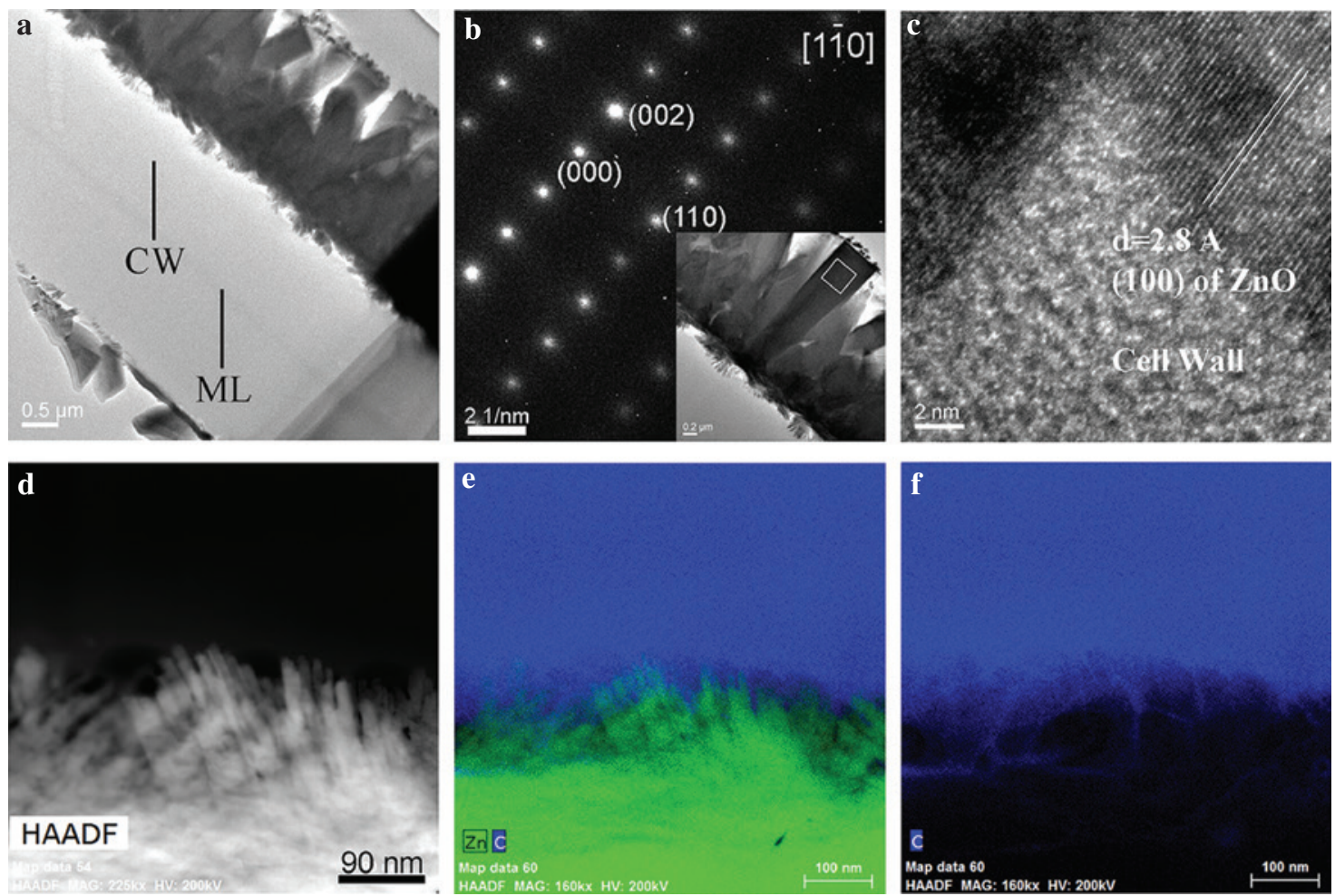

Figure 4: (a) TEM image of wood lamella with $\mathrm{ZnO}$ platelet coating (cell wall=CW, middle lamella=ML); (b) SAED pattern from the square area noted in the inset; (c) HRTEM image from the $\mathrm{ZnO}$ and wood cell wall interface; (d) HAADF-STEM image acquired from the $\mathrm{ZnO}$ and wood cell wall interface; (e) and (f) EDS-Mapping on the area shown in (d). Note: (e) is extracted from both zinc and carbon, while (f) is extracted from carbon. 
image of the interface between the wood cell wall and $\mathrm{ZnO}$ nanostructure in Figure 4c showed $\{100\}$ lattice planes of hexagonal $\mathrm{ZnO}$ as well as the diffraction contrast image from cellulose crystals in the wood cell wall. This latticeresolved image indicates that the $\mathrm{ZnO}$ platelets are closely intertwined with the wood cell wall. This could result from the binding of $\mathrm{Zn}\left[(\mathrm{OH})_{\mathrm{x}}\left(\mathrm{NH}_{3}\right)_{\mathrm{y}}\right)^{2 \cdot \mathrm{x}}$ complexes (Danilov et al. 1976) to hydroxyl and carbonyl groups of the wood cell wall polymers causing strong interactions between the wood and the ZnO layer (Katepetch et al. 2013). The strong adhesion resulting from the coupling of Ti-based agent to wood surface was also reported (Rasmussen et al. 2014).

Such coordination effects cause a blue shift of the carbonyl band, which was confirmed by FT-IR spectroscopy. The native spruce wood has an absorption in the region between $1700 \mathrm{~cm}^{-1}$ and $1750 \mathrm{~cm}^{-1}$ in the FT-IR spectrum due to the $\mathrm{C}=\mathrm{O}$ stretch in non-conjugated aliphatic carbonyls of holocellulose (Figure 5, curve b) (Lebo etal. 1990). While this peak faded away after treatment with the seeding solution (Figure 5, curve a), a new absorption signal emerged at 1631 $\mathrm{cm}^{-1}$, which might belong to $v_{\text {as }}(\mathrm{HNH})$ of $\mathrm{Zn}\left[(\mathrm{OH})_{\mathrm{x}}\left(\mathrm{NH}_{3}\right)_{\mathrm{y}}\right]^{2 \cdot \mathrm{x}}$ (Avirah et al. 2008). According to the HAADF-STEM image (Figure 4d), the seeding layer penetrates into the wood cell wall where nanowhiskers were formed which allow for a strong adherence of the $\mathrm{ZnO}$ nanostructures to the wood. EDS elemental mapping (Figure $4 \mathrm{e}$ and $\mathrm{f}$ ) acquired from the area shown in Figure 4d, demonstrated, that the wood fibres were closely interwoven with $\mathrm{ZnO}$ whiskers. The strong interaction between the wood surface and the $\mathrm{ZnO}$ coating can contribute to a good surface stability, which is particularly needed in outdoor applications, where the surface has to resist the natural weathering conditions (rain, wind, and hail) along with UV-light irradiation.

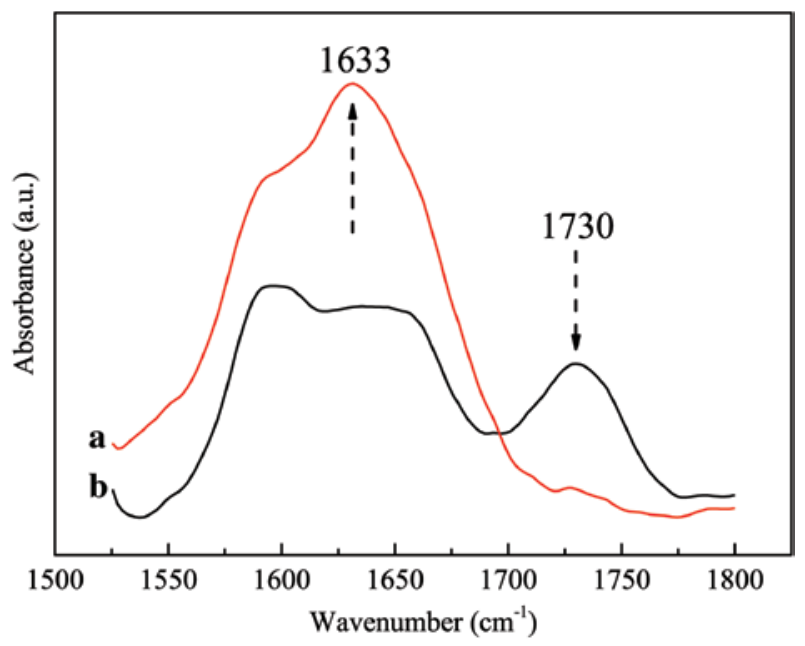

Figure 5: FT-IR spectra of spruce wood after treatment with the seeding solution (a) and spruce wood (b).
The UV protection efficiency of the modified wood surface was assessed by colour measurements after UV exposure (Figure 6). The occurrence of colour changes on the surface of the wood samples is related to the increasing number of chromophores produced during irradiation, which mainly results from the photo-oxidation of lignin (Müller et al. 2003; Rosu et al. 2010). During the UV exposure, the unmodified sample lost lightness from 77.9 to 69.5 , while the modified samples experienced a minute increment (Figure 6a). The lightness increased from 73.9 to 75.2 and 74.5 to 76.8 in the sample with dense $\mathrm{ZnO}$ coating and the sample with $\mathrm{ZnO}$ nanorod coating, respectively. The redness index $\left(a^{*}\right)$ of the unmodified sample underwent a decrease in the first $6 \mathrm{~h}$ and then increased up to 8.0 (Figure $6 \mathrm{~b}$ ). In the sample with $\mathrm{ZnO}$ nanorod coating, $a^{*}$ increased from 0.3 to 1.1. However, $a^{*}$ index decreased from 0.34 to -0.54 and then remained constant during the irradiation for the dense $\mathrm{ZnO}$ coating sample. Figure 6c demonstrates that the non-modified spruce has an apparent yellow shift with an increment in the value of $b^{*}$ from 25.8 to 32.9. However, for the sample with dense $\mathrm{ZnO}$ coating, $b^{*}$ slightly decreased from 14.8 to 11.36 in the first $18 \mathrm{~h}$, and further experienced a slow increment to finally reach 12.3. A similar trend was observed for the sample with $\mathrm{ZnO}$ nanorod coating. The total colour difference $(\Delta E)$ as a function of the irradiation time is given in Figure $6 \mathrm{~d} . \Delta E$ shows a strong rise with increasing irradiation time for unmodified spruce, which is visible in a total colour change of 11 after $102 \mathrm{~h}$ of UV exposure. In comparison, the total colour change of both modified sample is clearly restricted (about 3.0). $\Delta E$ of $\mathrm{ZnO}$ nanorod coated sample is lower than that of the sample with dense $\mathrm{ZnO}$ coating in the initial stage, but it increases as the exposure time is prolonged. These results demonstrate that the nanorod and the dense $\mathrm{ZnO}$ coating almost equally protected the wood surface against colour changes induced by UV exposure.

For further evaluation of the UV degradation, changes in the chemical structure of wood were analysed by FT-IR spectroscopy (Figure 7). In the spectrum of the blank spruce (not irradiated, curve b), the absorption centred at $1507.3 \mathrm{~cm}^{-1}$ is due to lignin, while the weak absorption centered at $1730.7 \mathrm{~cm}^{-1}$ is a polysaccharide vibration $(\mathrm{C}=\mathrm{O}$ stretch in non-conjugated ketones, carbonyl and ester groups) (Owen and Thomas 1989; Müller et al. 2003). The UV irradiation leads to significant changes in the FT-IR spectra of the wood surface without coating (curve c). The lignin band at $1507.3 \mathrm{~cm}^{-1}$ disappeared after $102 \mathrm{~h}$ of UV exposure, and was accompanied by the formation of strong carbonyl absorption centered on $1723.1 \mathrm{~cm}^{-1}$ (nonconjugated aliphatic carbonyls) (Leary 1968; Lebo et al. 

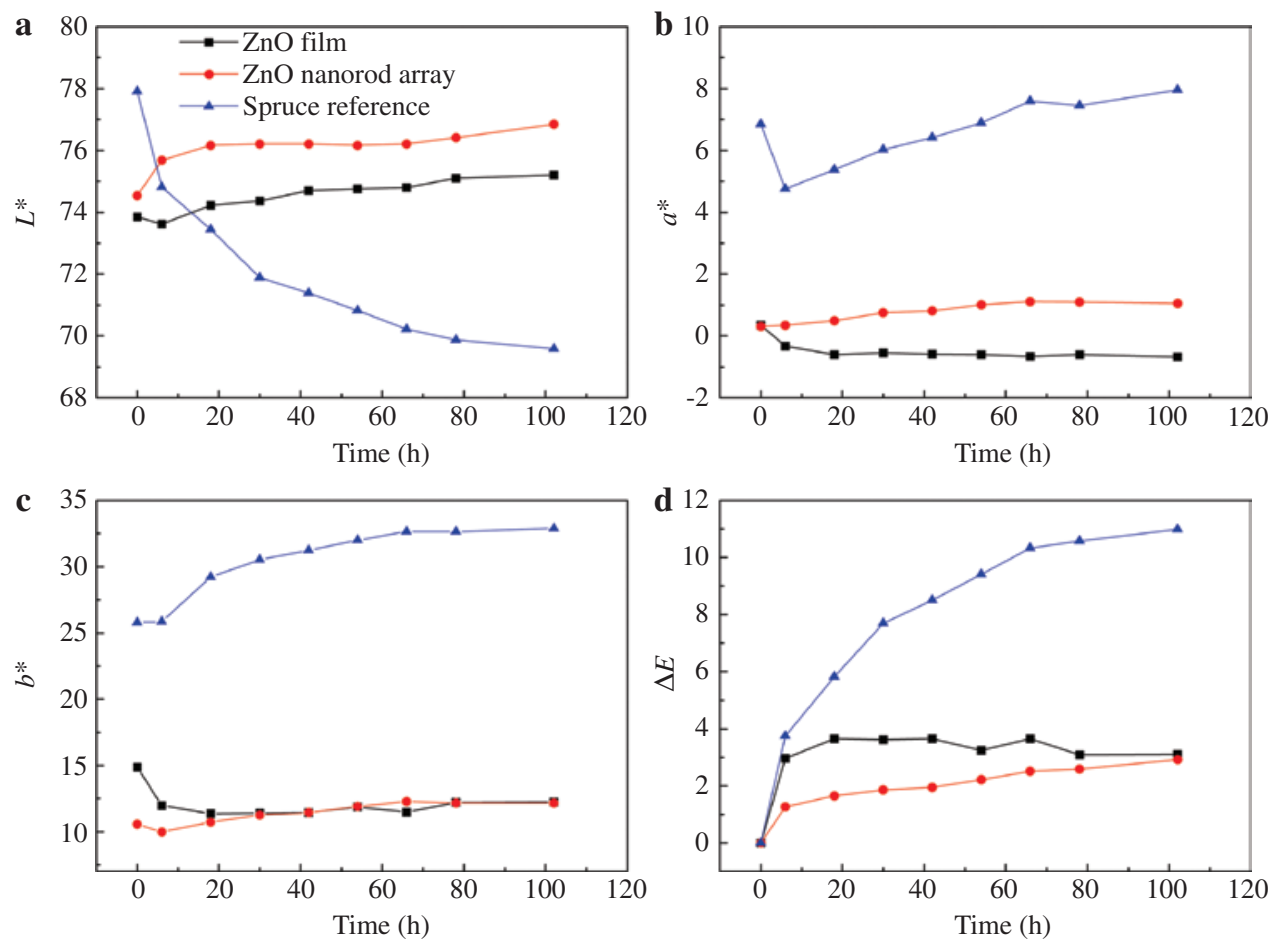

Figure 6: Dependence of lightness factor ( $\left.L^{*}\right)(\mathrm{a})$, redness factor $\left(a^{*}\right)(\mathrm{b})$, yellowness $\left(b^{*}\right)(\mathrm{c})$ and total colour change $\Delta E(\mathrm{~d})$ of coated and uncoated wood versus the irradiation time. ( $\bullet$ ) Spruce with dense ZnO coating; $(\bullet)$ spruce with ZnO nanorod coating and $(\boldsymbol{\Delta})$ non-modified spruce.

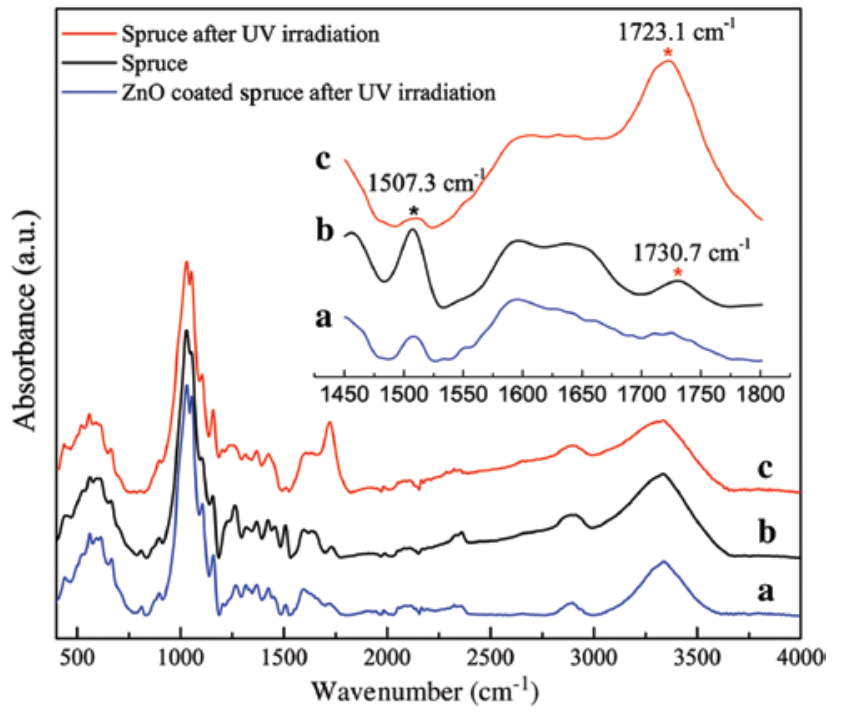

Figure 7: FT-IR spectra of the ZnO coated spruce wood after UV irradiation (a), spruce wood before (b) and after (c) UV irradiation. Inset: zoom of the carbonyl and aromatic absorption region.

1990). To check the effect of the dense $\mathrm{ZnO}$ coating after UV exposure, the coating layer was removed via ultrasonic treatment in $2 \% \mathrm{HCl}$. The FT-IR spectrum (curve a) was acquired from the surface after drying in the oven at $65^{\circ} \mathrm{C}$ for $3 \mathrm{~h}$. The aromatic lignin band at $1507.3 \mathrm{~cm}^{-1}$, as well as the $\mathrm{C}=\mathrm{O}$ stretch of conjugated or aromatic ketones (between 1600 and $1700 \mathrm{~cm}^{-1}$ ) show a slight decrease, but there is no band increment between 1700 and $1750 \mathrm{~cm}^{-1}$, which indicates that the UV induced photo-oxidation was suppressed by the $\mathrm{ZnO}$ coating.

Conclusive are the FT-IR spectra taken from different depth of UV exposed samples. As shown in Figure 8a and $\mathrm{b}$, the wood without any treatment exhibits a strong absorbance at $1509 \mathrm{~cm}^{-1}$ (aromatic rings of lignin). The bands located between $1700-1760 \mathrm{~cm}^{-1}$ and $1650-1700 \mathrm{~cm}^{-1}$ correspond to the absorbance of non-conjugated aliphatic carbonyls and conjugated/aromatic carbonyls, respectively (Müller et al. 2003). The UV exposure significantly changed the intensity of the IR spectra of unprotected wood. The influence of UV light on wood with dense $\mathrm{ZnO}$ coating is presented in Figure 8c and d. The intensity of aromatic band (point 1) is lower at the outmost layer, but constant from the second measuring point (point 2) to the firth one (point 5). Accordingly, the aromatic rings of lignin are well preserved by the $\mathrm{ZnO}$ coating, and a weak photo-oxidation only occurs in the outmost wood surface exposed to UV. Moreover, the intensity ratio of the bands aromatic lignin to carbonyls is higher in $\mathrm{ZnO}$ coated spruce (Figure 8c) when compared to their counterparts in unmodified wood 

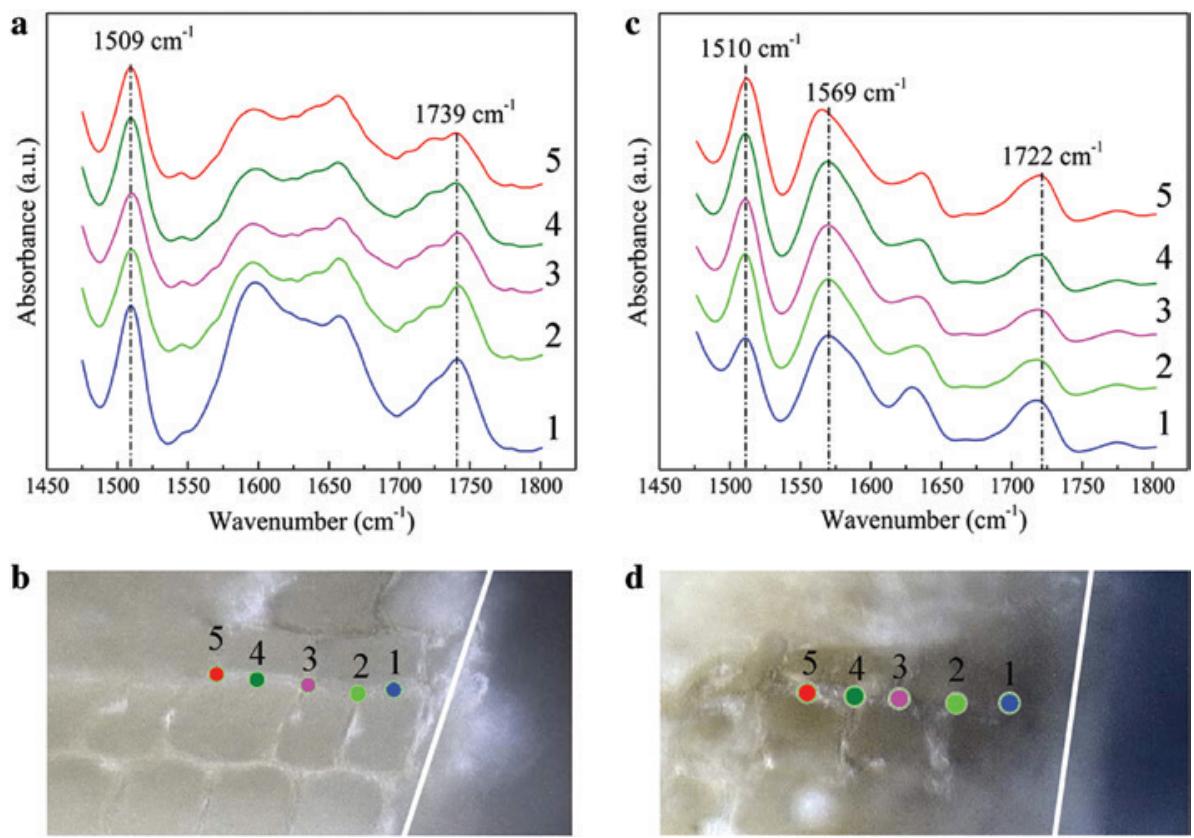

Figure 8: FT-IR spectra acquired from the cross section of spruce wood without coating (a) as well as the one with $\mathrm{ZnO}$ coating after $102 \mathrm{~h}$ of UV treatment (c). The spectra were acquired along middle lamella from the top (point 1) to the third cell layer (point 5) as noted in (b) and (d), respectively.

at various depths. This difference results presumably from the coordination effect of Zinc ammine complexes to the carbonyl groups in wood (Avirah et al. 2008; Katepetch et al. 2013) during the seeding and growth process.
Accelerated weathering tests were also carried out based on the European standard: EN 927-6:2006. Figure 9a displays the photographs of non-modified and modified wood samples with and without weathering. The wood

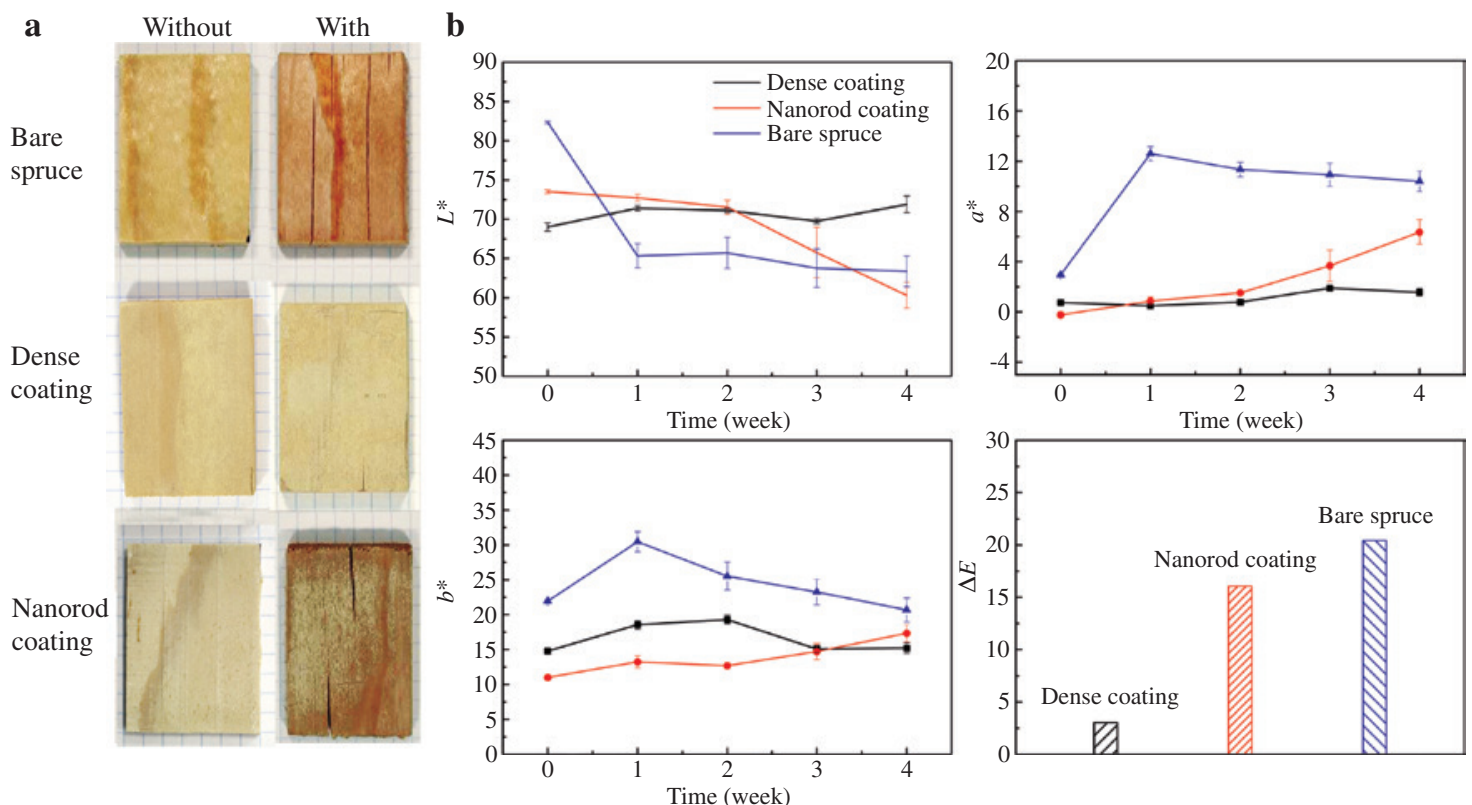

Figure 9: (a) Visualization of the effect of an accelerated weathering test (4 cycles) for an unmodified spruce sample and spruce samples coated with a dense ZnO layer and a nanorod ZnO layer, respectively. Please note that samples shown with and without weathering treatment are different, but similarly prepared for each category. (b) Progression of lightness $\left(L^{*}\right)$, redness ( $\left.a^{*}\right)$, yellowness $\left(b^{*}\right)$ and total color changes $\Delta E$ during the weathering test for an unmodified spruce sample and spruce samples coated with a dense $\mathrm{ZnO}$ layer and a nanorod $\mathrm{ZnO}$ layer, respectively. 
slices undergo swelling under the strong water spray $\left(8 \mathrm{~min}^{-1}\right)$ followed by shrinking due to steep rise in temperature to $60^{\circ} \mathrm{C}$ (in about $10 \mathrm{~min}$ ). As a result, cracking is observed on the bare spruce slice after the weathering test additionally to colour change. The colour of the surface protected by a dense $\mathrm{ZnO}$ coating shows only a slight surface haze and no colour change. The $\mathrm{ZnO}$ coating is more water resistant and suppresses immediate dimensional changes and crack formation and also serves for UV protection. In contrast, $\mathrm{ZnO}$ nanorod coating, could be partly dissolved and then washed away during the strong water spray, which resulted in both, strong colour changes and crack formation of the sample after four cycles of accelerated weathering test. As shown in Figure $9 \mathrm{~b}$, the colour change of the $\mathrm{ZnO}$ coated wood is about three during the durability test. The unmodified and $\mathrm{ZnO}$ nanorod coated wood displayed total colour changes of 20.4 and 16.1, respectively. These results demonstrate that the $\mathrm{ZnO}$ nanorod coating has an equal performance as the dense $\mathrm{ZnO}$ coating in terms of UV protection, but it is not stable in the presence of water spraying. This limits the outdoor application of the $\mathrm{ZnO}$ nanorod coated wood materials.

\section{Conclusions}

The uneven and inhomogeneous wood surface can be coated with conformal $\mathrm{ZnO}$ layers via chemical bath deposition making use of the coordination effect of Zinc ammine complexes to hydroxyl and carbonyl groups of lignocellulose. The morphologies of $\mathrm{ZnO}$ coatings were tunable from rough nanorod arrays to continuous and dense films by means of different structure directing agents. While nanorods and dense layers perform almost equally when exposed to UV light exclusively, the harsher weathering treatment reveals that the dense coating is more tightly bound to the wood surface and therefore more durable. Further, the dense film renders the coating more transparent, and almost preserves the aesthetic appeal of the wood surface. In-depth analysis performed by S/TEM indicates a wood surface interlocking with $\mathrm{ZnO}$ whiskers at the interface, which explains the strong interaction between the inorganic coating and the wood cell walls.

Acknowledgments: The authors gratefully acknowledge financial support by EIT Climate-KIC in the framework of the BTA flagship program (Building technology accelerator). We thank the BAFU (Bundesamt für Umwelt) and Lignum, Switzerland for the support of the chair of
Wood Materials Science. Electron microscopy studies were carried out at the ETH Scientific Center for Optical and Electron Microscopy (ScopeM). We thank Joakim Reuteler, Robin Schäublin, Willa Christoph and Beatrice Fischer for their assistance and discussion.

\section{References}

Aloui, F., Ahajji, A., Irmouli, Y., George, B., Charrier, B., Merlin, A. (2007) Inorganic UV absorbers for the photostabilisation of wood-clearcoating systems: comparison with organic UV absorbers. Appl. Surf. Sci. 253:3737-3745.

Auclair, N., Riedl, B., Blanchard, V., Blanchet, P. (2011) Improvement of photoprotection of wood coatings by using inorganic nanoparticles as ultraviolet absorbers. For. Prod. J. 61:20-27.

Auffan, M., Masion, A., Labille, J., Diot, M.A., Liu, W., Olivi, L., Proux, O., Ziarelli, F., Chaurand, P., Geantet, C., Bottero, J.Y., Rose, J. (2014) Long-term aging of $\mathrm{a} \mathrm{CeO}_{2}$ based nanocomposite used for wood protection. Environ. Pollut. 188:1-7.

Avirah, R.R., Jyothish, K., Ramaiah, D. (2008) Infrared absorbing croconaine dyes: synthesis and metal ion binding properties. J. Org. Chem. 73:274-279.

Baur, S.I., Easteal, A.J. (2013) Improved photoprotection of wood by chemical modification with silanes: NMR and ESR studies. Poly. Adv. Technol. 24:97-103.

Cho, S., Jang, J.-W., Jung, S.-H., Lee, B.R., Oh, E., Lee, K.-H. (2009) Precursor effects of citric acid and citrates on $\mathrm{ZnO}$ crystal formation. Langmuir 25:3825-3831.

Clausen, C.A., Green, F., Kartal, S.N. (2010) Weatherability and leach resistance of wood impregnated with nano-zinc oxide. Nanoscale Res. Lett. 5:1464-1467.

Danilov, V.V., Ravdel, A.A., Lutsik, V.P. (1976) Study of the solubility of zinc oxide and hydroxide in aqueous solutions of ammonia. Zh. Organich. Khim. 46:976-981.

Deka, M., Humar, M., Rep, G., Kricej, B., Sentjurc, M.S., Petric, M. (2008) Effects of UV light irradiation on colour stability of thermally modified, copper ethanolamine treated and nonmodified wood: EPR and DRIFT spectroscopic studies. Wood Sci. Technol. 42:5-20.

Fu, Y., Fu, W., Liu, Y., Zhang, G., Liu, Y., Yu, H. (2015) Comparison of $\mathrm{ZnO}$ nanorod array coatings on wood and their UV prevention effects obtained by microwave-assisted hydrothermal and conventional hydrothermal synthesis. Holzforschung 69:1009-1014.

Gao, L., Lu Y., Li, J., Sun, Q. (2016) Superhydrophobic conductive wood with oil repellency obtained by coating with silver nanoparticles modified by fluoroalkyl silane. Holzforschung 70:63-68.

George, B., Suttie, E., Merlin, A., Deglise, X. (2005) Photodegradation and photostabilisation of wood - the state of the art. Polym. Degrad. Stabil. 88:268-274.

Greene, L.E., Yuhas, B.D., Law, M., Zitoun, D.,Yang, P. (2006) Solution-grown zinc oxide nanowires. Inorg. Chem. 45: 7535-7543.

Grüneberger, F., Künniger, T., Zimmermann, T., Arnold, M. (2014a) Nanofibrillated cellulose in wood coatings: mechanical 
properties of free composite films. J. Mater. Sci. 49: 6437-6448.

Grüneberger, F., Künniger, T., Zimmermann, T., Arnold, M. (2014b) Rheology of nanofibrillated cellulose/acrylate systems for coating applications. Cellulose 21:1313-1326.

Hagendorfer, H., Lienau, K., Nishiwaki, S., Fella, C.M., Kranz, L., Uhl, A.R., Jaeger, D., Luo, L., Gretener, C., Buecheler, S., Romanyuk, Y.E., Tiwari, A.N. (2014) Highly transparent and conductive $\mathrm{ZnO}$ : Al thin films from a low temperature aqueous solution approach. Adv. Mater. 26:632-636.

Hernandez, V.A., Evans, P.D. (2015) Technical note: melanization of the wood-staining fungus Aureobasidium pullulans in response to UV radiation. Wood Fiber Sci. 47:120-124.

Hoang, S., Berglund, S.P., Fullon, R.R., Minter, R.L., Mullins, C.B. (2013) Chemical bath deposition of vertically aligned $\mathrm{TiO}_{2}$ nanoplatelet arrays for solar energy conversion applications. J. Mater. Chem. A 1:4307-4315.

Hon, D.N.S. (1995) Stabilization of wood color: is acetylation blocking effective? Wood Fiber Sci. 27:360-367.

Joo, J., Chow, B.Y., Prakash, M., Boyden, E.S., Jacobson, J.M. (2011) Face-selective electrostatic control of hydrothermal zinc oxide nanowire synthesis. Nat. Mater. 10:596-601.

Katepetch, C., Rujiravanit, R., Tamura, H. (2013) Formation of nanocrystalline $\mathrm{ZnO}$ particles into bacterial cellulose pellicle by ultrasonic-assisted in situ synthesis. Cellulose 20:1275-1292.

Lahtela, V., Kärki, T. (2014) Improving the UV and water-resistance properties of Scots pine (Pinus sylvestris) with impregnation modifiers. Eur. J. Wood Prod. 72:445-452.

Law, M., Greene, L.E., Johnson, J.C., Saykally, R., Yang, P. (2005) Nanowire dye-sensitized solar cells. Nat. Mater. 4:455-459.

Law, M., Greene, L.E., Radenovic, A., Kuykendall, T., Liphardt, J.,

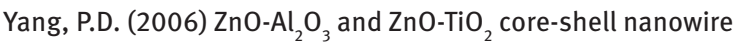
dye-sensitized solar cells. J. Phys. Chem. B 110:22652-22663.

Leary, G. (1968) Photochemical production of quinoid structures in wood. Nature 217:672-673.

Lebo, S.E., Lonsky, W.F.W., Mcdonough, T.J., Medvecz, P.J., Dimmel, D.R. (1990) The occurrence and light-induced formation of ortho-quinonoid lignin structures in white spruce refiner mechanical pulp. J. Pulp Pap. Sci. 16:J139-J143.

Liu, Y., Fu, Y., Yu, H., Liu, Y. (2013) Process of in situ forming well-aligned zinc oxide nanorod arrays on wood substrate using a two-step bottom-up method. J. Colloid Interface Sci. 407:116-121.

Liu, Y., Shao, L., Gao, J., Guo, H., Chen, Y., Cheng, Q., Via, B.K. (2015) Surface photo-discoloration and degradation of dyed wood veneer exposed to different wavelengths of artificial light. Appl. Surf. Sci. 331:353-361.

Lu, Y., Xiao, S., Gao, R., Li, J., Sun, Q. (2014) Improved weathering performance and wettability of wood protected by $\mathrm{CeO}_{2}$ coating deposited onto the surface. Holzforschung 68:345-351.

Mahr, M.S., Hübert, T., Stephan, I., Bücker, M., Militz, H. (2013) Reducing copper leaching from treated wood by sol-gel derived $\mathrm{TiO}_{2}$ and $\mathrm{SiO}_{2}$ depositions. Holzforschung 67:429-435.

Müller, U., Rätzsch, M., Schwanninger, M., Steiner, M., Zöbl, H. (2003) Yellowing and IR-changes of spruce wood as result of UV-irradiation. J. Photoch. Photobio. B 69:97-105.

Niederberger, M., Pinna, N., Polleux, J., Antonietti, M. (2004) A general soft-chemistry route to perovskites and related materials: synthesis of $\mathrm{BaTiO}_{3}, \mathrm{BaZrO}_{3}$, and $\mathrm{LiNbO}_{3}$ nanoparticles. Angew. Chem. Int. Ed. 43:2270-2273.
Owen, N.L., Thomas, D.W. (1989) Infrared studies of "hard" and "soft" woods. Appl. Spectrosc. 43:451-455.

Plackett, D.V., Dunningham, E.A., Singh, A.P. (1992) Weathering of chemically modified wood. Holz Roh. Werkst. 50:135-140.

Rao, X., Liu, Y., Fu, Y., Liu, Y., Yu, H. (2016) Formation and properties of polyelectrolytes $/ \mathrm{TiO}_{2}$ composite coating on wood surfaces through layer-by-layer assembly method. Holzforschung 70:361-367.

Rasmussen, J.S., Barsberg, S., Felby, C. (2014) Complex between lignin and a Ti-based coupling agent. Holzforschung 68: 541-548.

Rassam, G., Abdi, Y., Abdi, A. (2012) Deposition of $\mathrm{TiO}_{2}$ nanoparticles on wood surfaces for UV and moisture protection. J. Exp. Nanosci. 7:468-476.

Rosu, D., Teaca, C.-A., Bodirlau, R., Rosu, L. (2010) FTIR and color change of the modified wood as a result of artificial light irradiation. J. Photoch. Photobio. B 99:144-149.

Rowell, R.M. (2006) Chemical modification of wood: a short review. Wood Mater. Sci. Eng. 1:29-33.

Salla, J., Pandey, K.K., Srinivas, K. (2012) Improvement of UV resistance of wood surfaces by using $\mathrm{ZnO}$ nanoparticles. Poly. Degrad. Stabil. 97:592-596.

Sander, C., Koch, G. (2001) Effects of acetylation and hydrothermal treatment on lignin as revealed by cellular UV-spectroscopy in Norway spruce (Picea abies [L.] Karst.). Holzforschung 55:193-198.

Srinivas, K., Pandey, K.K. (2012) Photodegradation of thermally modified wood. J. Photochem. Photobio. B 117:140-145.

Sun, Q.F., Yu, H., Liu, Y., Li, J., Lu, Y., Hunt, J.F. (2010) Improvement of water resistance and dimensional stability of wood through titanium dioxide coating. Holzforschung 64:757-761.

Sun, Q.F., Lu, Y., Zhang, H.M., Yang, D.J., Wang, Y., Xu, J.S., Tu, J.C., Liu, Y.X., Li, J. (2012) Improved UV resistance in wood through the hydrothermal growth of highly ordered $\mathrm{ZnO}$ nanorod arrays. J. Mater. Sci. 47:4457-4462.

Tian, Z.R., Voigt, J.A., Liu, J., Mchenzie, B., Mcdermott, M.J., Rodriguez, M.A., Konishi, H., Xu, H. (2003) Complex and oriented ZnO nanostructures. Nat. Mater. 2:821-826.

Veronovski, N., Verhovsek, D., Godnjavec, J. (2013) The influence of surface-treated nano-TiO ${ }_{2}$ (rutile) incorporation in waterbased acrylic coatings on wood protectin. Wood Sci. Technol. 47:317-328.

Wang, X., Chai, Y., Liu, J. (2013) Formation of highly hydrophobic wood surfaces using silica nanoparticles modified with longchain alkylsilane. Holzforschung 67:667-672.

Wang, N., Fu, Y., Liu, Y., Yu, H., Liu, Y. (2014) Synthesis of aluminum hydroxide thin coating and its influence on the thermomechanical and fire-resistant properties of wood. Holzforschung 68:781-789.

Weichelt, F., Emmler, R., Flyunt, R., Beyer, E., Buchmeiser, M.R., Beyer, M. (2010) ZnO-based UV nanocomposites for wood coatings in outdoor applications. Macromol. Mater. Eng. 295:130-136.

Yu, Y., Jiang, Z., Wang, G., Song, Y. (2010) Growth of ZnO nanofilms on wood with improved photostability. Holzforschung 64:385-390.

Zahri, S., Belloncle, C., Charrier, F., Pardon, P., Qquideau, S., Charrier, B. (2007) UV light impact on ellagitannins and wood surface colour of European oak (Quercus petraea and Quercus robur). Appl. Surf. Sci. 253:4985-4989. 